\title{
HEAT PIPE EMBEDDED ALSIC PLATES FOR HIGH CONDUCTIVITY - LOW CTE HEAT SPREADERS
}

\author{
J. Weyant ${ }^{1}$, S. Garner ${ }^{1}$, M. Johnson ${ }^{2}$, M. Occhionero ${ }^{3}$ \\ ${ }^{1}$ Advanced Cooling Technologies, Inc \\ 1046 New Holland Ave, Lancaster, Pa 17601 \\ Phone: (717) 295-6093 \\ Fax: (717) 295-6064 \\ Email: jens.weyant@1-ACT.com
}

\author{
${ }^{2}$ National Nuclear Security Administration's Kansas City Plant \\ Operated by Honeywell Federal Manufacturing \& \\ Technologies, LLC \\ Phone: (816) 997-4172 \\ Email: $\underline{\text { mjohnson@kcp.com }}$
}

\author{
${ }^{3}$ CPS Technologies Corporation \\ 111 South Worcester Street, Norton, MA 02766 \\ Phone: (508) 222-0614 x242 \\ Fax: 508 222-0220 \\ Email: mocchionero@alsic.com
}

\begin{abstract}
Heat pipe embedded aluminum silicon carbide (AlSiC) plates are innovative heat spreaders that provide high thermal conductivity and low coefficient of thermal expansion (CTE). Since heat pipes are two phase devices, they demonstrate effective thermal conductivities ranging between 50,000 and $200,000 \mathrm{~W} / \mathrm{m}-\mathrm{K}$, depending on the heat pipe length. Installing heat pipes into an AlSiC plate dramatically increases the plate's effective thermal conductivity. AlSiC plates alone have a thermal conductivity of roughly $200 \mathrm{~W} / \mathrm{m}-\mathrm{K}$ and a CTE ranging from $7-12 \mathrm{ppm} /{ }^{\circ} \mathrm{C}$, similar to that of silicon. An equivalent sized heat pipe embedded $\mathrm{AlSiC}$ plate has effective thermal conductivity ranging from 400 to $500 \mathrm{~W} / \mathrm{m}-\mathrm{K}$ and retains the CTE of AlSiC.
\end{abstract}

KEYWORDS: High Thermal Conductivity, Heat Spreader, Low Coefficient of Thermal Expansion (CTE), Vapor Chamber, Electronics Cooling, Heat Pipe

\section{NOMENCLATURE}

Q Power, W

$\mathrm{k}$ Thermal Conductivity, W/m-K

A Area, $\mathrm{m}^{2}$

$\mathrm{x} \quad$ Thickness, $\mathrm{m}$

$\Delta \mathrm{T} \quad$ Temperature Difference, ${ }^{\circ} \mathrm{C}$ or $\mathrm{K}$

\section{BACKGROUND}

\subsection{Electronics Packaging}

Thermal management is important for the performance and reliability of today's high power and high density microelectronics systems. Ideal packaging materials must have high thermal conductivity and CTE values that are compatible with the IC device, attached substrates and assembly, while remaining light weight and affordable. Packaging materials with device and substrate compatible CTE values minimize the thermally induced stresses during power cycling. Thermal stresses often result in device cracking failure, or by the delamination of substrates that disrupts the thermal dissipation path causing electronics thermal failure. CTE compatibility allows substrates/solder layers to be optimized by reducing thickness to take full advantage of packaging material thermal conductivity and the integrated cooling systems.

Lightweight, high strength stiffness packaging materials minimize failures due to shock and vibration in service as well as shock that occurs during high speed automated assembly. Lightweight materials also eliminate orientation dependences for integrated heat sink lids applied on top of microprocessors and in flip chip applications. Larger and more functional packages designs can be considered to enable the integration of many electronics systems with lighter weight packaging materials.

\subsection{AlSiC}

Aluminum silicon carbide ( $\mathrm{AlSiC}$ ) is a metal matrix composite (MMC) well suited for electronics packaging. As shown in Fig 1, AlSiC is composed of discrete silicon carbide particles surrounded by a continuous Al-metal phase.

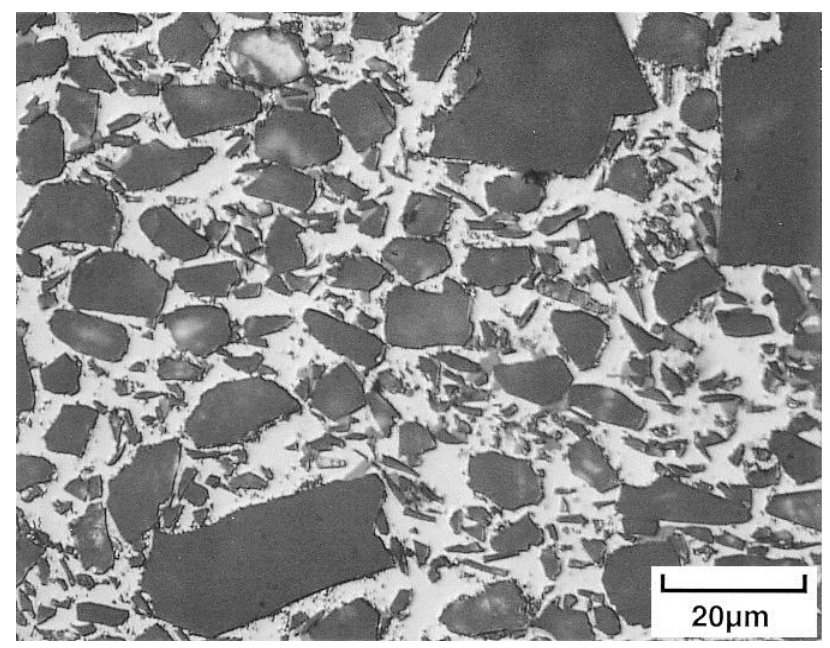

Fig 1: AlSiC Microstructure with the discrete $\mathrm{SiC}$ particles surrounded in a continuous Al-metal phase 
The coefficient of thermal expansion (CTE) can be specifically tailored with CTE values ranging from 7-12 $\mathrm{ppm} /{ }^{\circ} \mathrm{C}$ by controlling the composition of $\mathrm{Al}$ and $\mathrm{SiC}$, so that direct IC device attachment is possible [1]. AlSiC has a low density of $3 \mathrm{~g} / \mathrm{cm}^{3}$ which is favorable for weight sensitive applications. Its strength and stiffness are approximately three times greater than that of pure aluminum, making AlSiC ideal for structural thermal management solutions as well [2].

\subsection{Heat Pipes}

Heat pipes transport heat by two phase flow of a working fluid $[3,4]$. Shown in Fig 2, a heat pipe is a vacuum tight device consisting of a working fluid and a wick structure. The heat input vaporizes the liquid working fluid inside the wick in the evaporator section. The vapor, carrying the latent heat of vaporization, flows towards the cooler condenser section. In the condenser, the vapor condenses and gives up its latent heat. The condensed liquid returns to the evaporator through the wick structure by capillary action. The vapor space of the heat pipe is at saturated conditions, so the end to end heat pipe temperature difference is generally less than $2^{\circ} \mathrm{C}[5,6]$.

Copper/water heat pipes are standard for electronics cooling. Water and copper are known to be compatible for long term operation. In the temperature range of typical electronics cooling environments $\left(25^{\circ} \mathrm{C}\right.$ to $\left.125^{\circ} \mathrm{C}\right)$, water has the best combination of physical properties (surface tension, latent heat, viscosity, etc.) for heat pipe performance. Copper also has the highest thermal conductivity of any engineering metal, making it ideal for heat transfer applications. Copper's flexibility makes it ideal for conforming to different desirable geometries, allowing them to be bent and flattened to conform to flat input surfaces or avoid structures. Since heat pipes are essentially isothermal along their length, their effective thermal conductivity can range from 50,000 to $200,000 \mathrm{~W} / \mathrm{m}$ K.

\subsection{Heat Pipe Embedded Plates}

Heat pipe embedded aluminum plates are used as heat spreaders and in some cases also as a structural member in electronics packaging. Embedding heat pipes increases the effective thermal conductivity by several factors without negatively affecting the plate's mass, strength, or corrosion resistance. In general, the performance of a heat pipe embedded $\mathrm{Al}$ plate is equivalent to that of the high end composite materials, but cost much less to manufacture.

Typical applications involve mounting multiple high power electronic devices on the heat pipe embedded Al plate, which collects and moves heat with minimal temperature gradients. Fig 3 is an image of a heat pipe embedded $\mathrm{Al}$ plate. Here the heat pipes were soldered into straight and bent grooves to optimize heat transport.

The layout of the embedded heat pipes may be optimized based on the heat source profiles and locations. A higher number of heat pipes may be embedded in areas on the plate where large heat sources are attached. Even with the embedded heat pipes, the heat pipe embedded plate weighs less than an equivalently sized conventional Al plate.

Depending on the application, survivability in cold ambient conditions requires the heat pipes to be tolerant of numerous freeze/thaw cycles. Also surface coatings and finishes may be applied to the heat pipe embedded $\mathrm{Al}$ plates to provide weather resistance as required by specific applications.

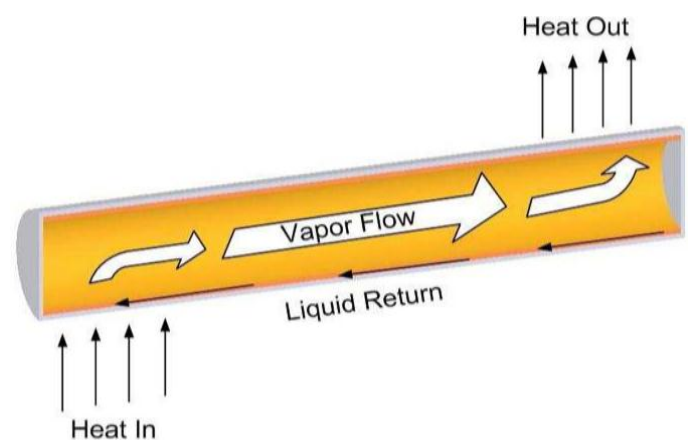

Fig 2: The operation of a heat pipe is illustrated. Heat applied to one end of the heat pipe evaporates liquid off a wick. The

vapor carrying its heat of vaporization moves toward the colder end of the heat pipe where it condenses. The wick returns fluid to the evaporator.

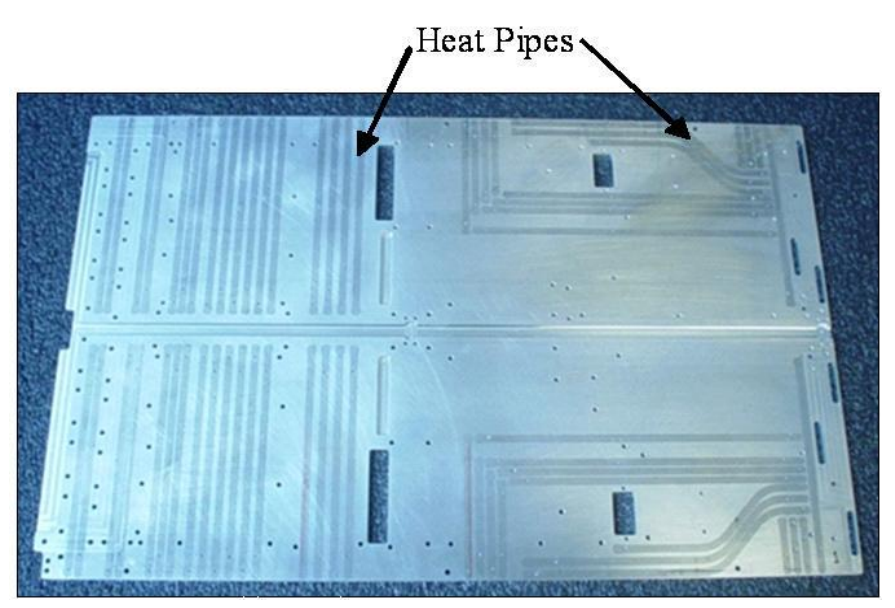

Fig 3: Heat pipes soldered into an Al cold plate greatly increase the thermal conductivity of traditional Al plates.

\section{EXPERIMENTAL}

\subsection{Fabrication}

AlSiC plates from CPS Technologies were obtained for this study. $\mathrm{SiC}$ is abrasive and is difficult to machine, so the AlSiC plates delivered from CPS were pre-formed with the necessary features and dimensions. These plates were functionally graded from a $\mathrm{SiC}$ rich face to an $\mathrm{Al}$ rich face. The Al rich side of the plate had grooves made especially for heat pipe embedment. Copper water heat pipes fabricated at $\mathrm{ACT}$ were soldered into the grooves within the $\mathrm{Al}$ rich face, using $63 \mathrm{Sn}: 37 \mathrm{~Pb}$ solder. Post solder machining was 
performed to remove excess solder. Minimal tool wear was observed, confirming the benefit of the functionally graded AlSiC plate. The low CTE of the SiC rich face of the plate provides an excellent surface for electronic attachment, while the Al rich provides an optimum surface for joining to the ultimate heat sink, which is typically $\mathrm{Al}$.

\subsection{Thermal Testing}

The thermal performance of a pure AlSiC plate was compared to that of four heat pipe embedded plates. For this study, two different heat pipe wick structures were investigated (Wick \#1 and Wick \#2). Power ranging from $25 \mathrm{~W}$ to $150 \mathrm{~W}$ was applied to the center of the $\mathrm{SiC}$ rich side of the plates. Cartridge heaters were placed within a copper block with a $20 \mathrm{~mm} x$ $20 \mathrm{~mm}$ base area. This provides a max flux of $37.5 \mathrm{~W} / \mathrm{cm}^{2}$. The plates were edge cooled by flowing water through aluminum blocks at a rate of $25 \mathrm{gph}$ that were attached to the Al Rich side of the plate using clamps. Grafoil was used to minimize interface resistance between the plates and the heating and cooling sources. Figure 4 illustrates the test setup.

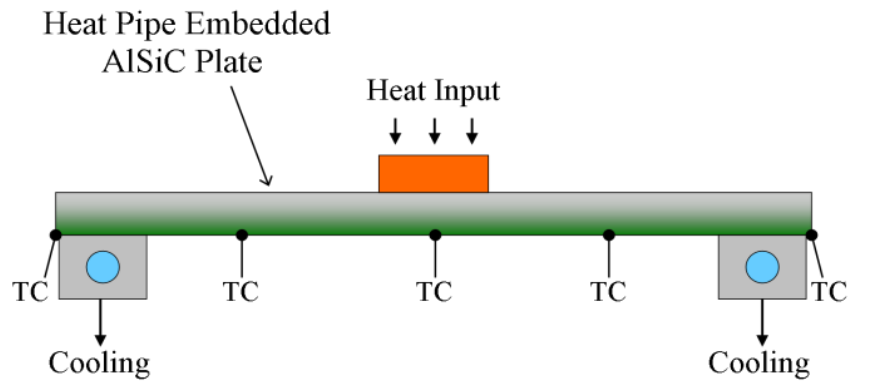

Fig 4: Heat Pipe Embedded Plate Test Apparatus. Heat is supplied through a $20 \mathrm{~mm} \times 20 \mathrm{~mm}$ area located in the center of the plate, and the edges a cooled using liquid flow through cooling blocks.

Temperatures were recorded at five different locations across the width of the plate using thermocouples, placed on the $\mathrm{Al}$ rich side of the plate. This configuration provides data showing the temperature gradient from the heat source to sink, which may be used to determine the plates effective thermal conductivity.

\subsection{Freeze/Thaw Testing}

Heat pipes embedded into the AlSiC plates use water as a working fluid, so wick design is essential for freeze thaw survivability. When designed properly, the heat pipe wick absorbs all of the working fluid. This prevents the working fluid, in this case water, from pooling within the pipe, thereby avoiding harmful expansion during freezing.

The heat pipe embedded AlSiC plates using different wick structures were exposed to thermal cycles ranging from $-55^{\circ} \mathrm{C}$ to $125^{\circ} \mathrm{C}$, at the Kansas City Plant. Once thermal cycling completed, the plates were returned to ACT for thermal testing. The thermal testing procedure described previously was followed.

\section{RESULTS}

\subsection{Temperature Gradients}

Figure 5 shows plots of the temperature gradients across the AlSiC only plate, as well as across a heat pipe embedded AlSiC plates using Wick \#1 and Wick \#2. When $150 \mathrm{~W}$ was applied to the center of the $\mathrm{AlSiC}$ only plate the maximum temperature observed was $124^{\circ} \mathrm{C}$, and the temperature difference $(\Delta \mathrm{T})$ across the plate was $92.6^{\circ} \mathrm{C}$. Heat pipe embedded AlSiC plates with Wick \#1 and Wick \#2 had respective maximum temperatures of $84^{\circ} \mathrm{C}$ and $75^{\circ} \mathrm{C}$, where Wick \#1 produced an average plate $\Delta \mathrm{T}=37.6^{\circ} \mathrm{C}$ and Wick \#2 produced an average plate $\Delta \mathrm{T}=44.4^{\circ} \mathrm{C}$.
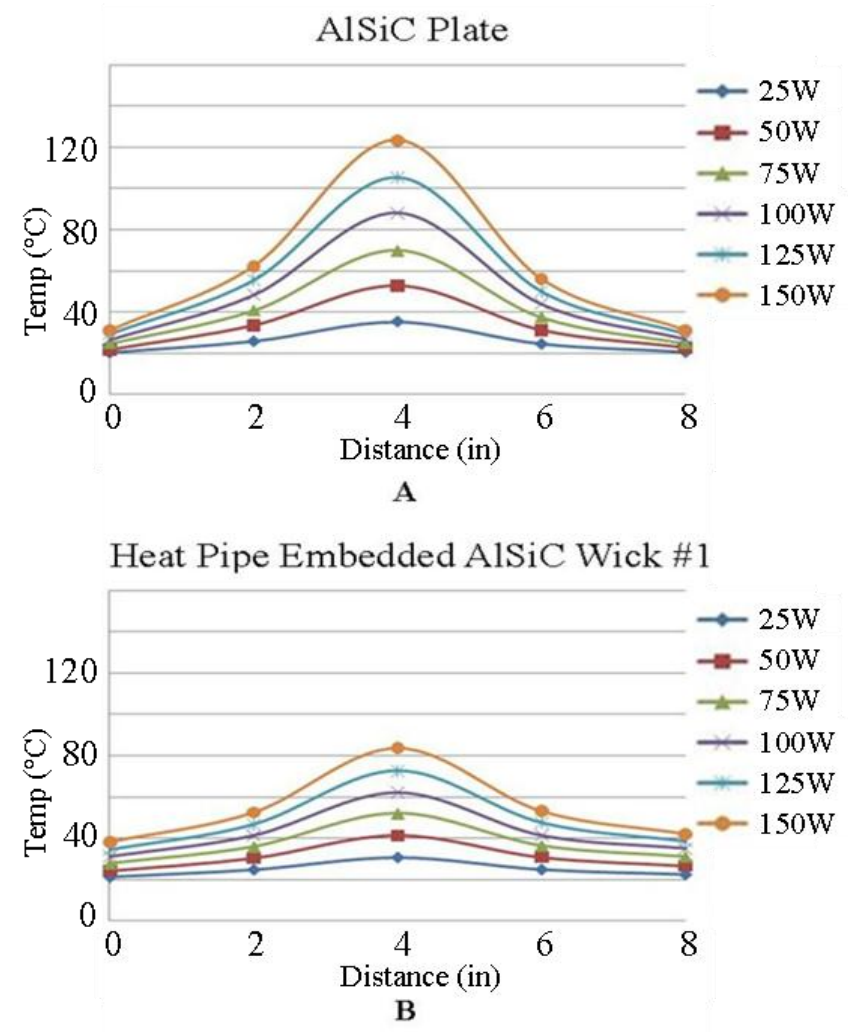

Heat Pipe Embedded AlSiC Wick \#2

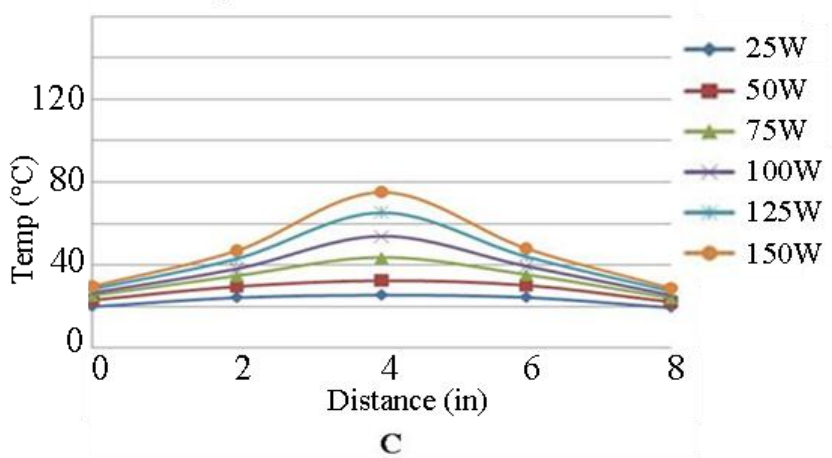

Figure 5: The temperature profiles across the A) Pure AlSiC plate, B) Heat pipe embedded AlSiC plate \#1, and C) heat pipe embedded AlSiC plate \#2, with heat inputs ranging from $25 \mathrm{~W}$ to $150 \mathrm{~W}$.

\subsection{Effective Thermal Conductivity}


A comparison can be made between the AlSiC-only plate and heat pipe embedded plates using Fourier's Law (Eq 1) to determine the heat pipe embedded AlSiC plate effective thermal conductivity $(\mathrm{k})$. By using data collected at $150 \mathrm{~W}$ input power, the power (Q), plate area (A), and plate thickness (x) are the same for all plates and can therefore be disregarded for the comparison. Using the known thermal conductivity of $\operatorname{AlSiC}\left(\mathrm{k}=200 \mathrm{~W} / \mathrm{m}^{-} \mathrm{K}\right)$ and the experimentally measured $\Delta \mathrm{T}$, the effective thermal conductivity of the heat pipe embedded AlSiC plates may be determined. The effective thermal conductivity for the heat pipe embedded plates using wick structure \#1 were found to be $492 \mathrm{~W} / \mathrm{m}-\mathrm{K}$ and for plates with wick structure \#2 were found to have an effective thermal conductivity of $417 \mathrm{~W} / \mathrm{m}-\mathrm{K}$.

\section{Eq 1: Fourier's Law}

$Q=\frac{k A}{x} \Delta T$

Effective thermal conductivity is largely affected by plate and heat pipe geometry. Heat pipes transfer heat through twophase and are essentially isothermal. This allows heat pipe embedded plates of different lengths (x) to maintain very similar temperature gradients. As the plate length $\mathrm{x}$ increases, with constant $\Delta \mathrm{T}$, thermal conductivity also increases. The effective thermal conductivity of a heat pipe embedded plate may also be increased by reducing plate $\Delta \mathrm{T}$ through optimizing heat pipe location.

\subsection{Post Freeze Thaw Analysis}

Plates exposed to thermal cycling from $-55^{\circ} \mathrm{C}$ to $125^{\circ} \mathrm{C}$ were tested for post freeze thaw thermal performance. Plates using both wick structures showed similar results to those observed during pre freeze thaw testing. The plate with wick structure \#1 has an effective thermal conductivity of $528 \mathrm{~W} / \mathrm{m}-\mathrm{k}$, while wick \#2 showed a thermal conductivity of $298 \mathrm{~W} / \mathrm{m}-\mathrm{K}$.

Heat pipe failure would result in an effective thermal conductivity measured similar to that of a pure AlSiC plate, and this was not observed. The difference between the pre and post freeze thaw thermal conductivity may be attributed to error between testing and possible degradation between the heat pipe AlSiC plate interface caused by CTE mismatch.

Initial results shows that the heat pipe embedded AlSiC plates survive freeze thaw testing. Only two plates were thermally tested after freeze thaw testing. Further investigation would require a statistically significant number of plates be examined before drawing any concrete conclusions regarding the heat pipe-AlSiC plate interface.

\section{CONCLUSION}

Embedding heat pipes into AlSiC plates significantly increases the effective thermal conductivity and is proven to be freeze thaw tolerant. Embedding heat pipes into AlSiC reduces the temperature gradient by over $50 \%$ in comparison to the AlSiC only plate. AlSiC has a thermal conductivity of $200 \mathrm{~W} / \mathrm{m}-\mathrm{k}$ and a CTE similar to that of silicon. Embedding heat pipes into AlSiC plates improved the effective thermal conductivity to $417-492 \mathrm{~W} / \mathrm{m}-\mathrm{K}$, depending on the heat pipe wick structure. For this study a very general design was used to embed the heat pipes into the AlSiC. The effective thermal conductivity of the AlSiC heat pipe embedded plate could be further increased by optimizing the heat pipe layout.

\section{ACKNOWLEDGEMENTS}

This manuscript has been authored by Honeywell Federal Manufacturing \& Technologies under Contract No.DE-ACO401AL66850 with the U.S. Department of Energy. The United States Government retains and the publisher, by accepting the article for publication, acknowledges that the United States Government retains a nonexclusive, paid-up, irrevocable, world-wide license to publish or reproduce the published form of this manuscript, or allow others to do so, for United States Government purposes.

\section{REFERENCES}

[1] Occhionero M.A., Hay R.A., et al., "Aluminum silicon Carbide (AlSiC) Microprocessor Lids and Heat Sinks for Integrated Thermal Management Solutions", IMAPS, Denver, April 26-28, 2000

[2] Occhionero M.A., Hay R.A., et al, "Aluminum Silicon Carbide (AlSiC) For Cost-Effective Thermal Management Packaging for High Density Packaging Applications", International Conference on High Density Packaging and MCM's, Denver, CO, April 6-9, 1999

[3] Faghri A., "Heat Pipe Science and Technology", Taylor \& Francis, Washington, DC. 1994

[4] Dunn P.D., Reay D.A., "Heat Pipes", Pergamon, Tarrytown, NY. 1994

[5] Collier J.G. Thome J.R., "Convective Boiling and Condensation", Oxford University Press, NY. 1994

[6] Incropera F.P., Dewitt D.P., "Fundamentals of Heat and Mass Transfer", John Wiley \& Sons, NY. 2002 